\title{
Identification of Individual Intolerance Behaviour Trends Through Thematic Apperception Test (TAT) Analysis
}

\author{
Gede Nugraha Sudarsana ${ }^{1, *}$ Ni Ketut Suarni ${ }^{1}$ \\ ${ }^{1}$ Guidance and Counseling Study Program, Universitas Pendidikan Ganesha, Singaraja, Indonesia \\ ${ }^{*}$ Corresponding author. Email: nugraha.sudarsana@undiksha.ac.id
}

\begin{abstract}
This study aims to describe the tendency of high school students' intolerance behavior by using Thematic Apperception Test (TAT) analysis. This research is descriptive. The sample in this study were high school / vocational students in Singaraja City, and data reduction was carried out using random sampling. Obtained a sample of 120 students from 3 schools. Data was collected using the Thematic Apperception Test. Data analysis uses categorization of the total score obtained by respondents based on TAT answers. Based on the results of the study, it was obtained that the indicators of the tendency of intolerance were dominated by the following indicators: insecure by $87 \%$, aggression by $75 \%$, assumptions by $70 \%$, prejudice by $60 \%$, and jealousy by $57 \%$. So it can be concluded that the Thematic Apperception Test (TAT) analysis can be used to identify individual intolerance behavior tendencies. These findings describe the manifestation of intolerance behavior that is interrelated between one indicator and another. The results of this study can be initial findings as an assessment method for educational institutions and related agencies in minimizing and capturing negative behavior.
\end{abstract}

Keywords: Intolerance, Tolerance, Thematic apperception test

\section{INTRODUCTION}

"The Highest Result of Education is Tolerance"Helen Keller, a quote by Hellen Keller which can be interpreted as the highest result of education is tolerance [1]. The quote may be difficult to digest for individuals who have the view that material results are the yardstick. Those who view that education is only to find skills or connections to later become a way to achieve "success" which of course will be seen from income, and prestige. Keller's quote above can be understood as a view that sees education holistically in addition to seeing the process and results in science and expertise, but also seeing how humans behave like humans. This is in line with Dewey's view that we often hear the words "humanizing humans" is to develop the human dimension towards the highest embodiment in every space of the human dimension [2].

From this, the researcher has the view that education is not only concerned with academic achievement, or emotional questions (EQ), but is more concerned with how these students can achieve the highest potential from the human dimension. The observation that researchers get from the current trend of education issues is to develop EQ, is it only by increasing EQ that we can state that education has humanized humans, of course not, EQ is indeed one of the spaces of the human dimension but there is another space that is forgotten by the teacher. The fatality of the tolerance space that should be the focus of educators is being forgotten. If in the end all the knowledge and concepts learned by an individual only produce an "expert", who is without empathy, logic, or common sense who only relies on knowledge, concepts, and connections, then of course this learning process cannot be said to have reached its peak.

Tolerance in the Big Indonesian Dictionary means a tolerant attitude that is "tolerating (appreciating, allowing, allowing) stances (opinions, views, beliefs, habits, behavior, and so on) that are different or contrary to one's stance" [3]. Indonesia as a multicultural country, of course, really needs this attitude of tolerance to maintain the cohesiveness of its nation. In the ideal concept, tolerance becomes a bridge that can deliver a cohesive and advanced Indonesian nation, of course starting from an early age with education, but in the field what happens is the development of tolerance space for 
students is ignored and even rejected altogether with excuses and reasons. which is even illogical, for example, the case that recently occurred the mandatory wearing of the headscarf on non-Muslim students in public schools [4], From this one example, we can see that if the tolerance attitude that is needed to be developed by students is even inhibited, the consequences of inhibiting the development of this tolerance attitude will certainly have an impact on the emergence of intolerant attitudes and behavior.

Intolerance is an attitude and even behavior that is dangerous for the Indonesian nation and state and especially for these individuals, divisions, identity conflicts, and antipathy that are ethnic, religious, racial and intergroup will be the consequences of this intolerance is allowed. Factors supporting the emergence of intolerance are also difficult to overcome, especially those from family education, therefore this attitude of intolerance that is considered trivial must be handled by educators and schools. Educators are expected to be able to recognize early on their students who tend towards intolerant behavior. This can be done by applying the Thematic Apperception Test (TAT). The TAT analysis model is an analytical model that is quite easy to apply to individual students, groups, and large groups. In summary, the TAT analysis process is to give the subject in this case the students ambiguous pictures and ask the students to tell dramatically what they captured from the pictures, from the story written by the subject and then interpreted by the teacher, next educators can clarify to subjects who are considered to tend to behave intolerantly. From the TAT analysis, it is hoped that schools and educators can integrate and guide their students in developing tolerant attitudes and behaviors. The purpose of this study is to describe the tendency of high school students' intolerance behavior by using Thematic Apperception Test (TAT) analysis.

\section{LITERATURE REVIEW}

\subsection{Tolerance and Intolerance}

Psychologically, high school students are individuals who are in their teens, where the period is turbulent (sturm and drang). Teenagers tend to be progressive and constantly want to try and change. Psychologically, students who are generally aged from 15-17 years who are classified as early teens, usually still have a followup attitude which is one of the positive attitudes that is formed in an attitude of tolerance. The attitude of curiosity that arises in students can motivate them to establish relationships with other friends of the same religion or different religions, and not only that, but the differences that exist among students [5].

According to Robinson et al., Tolerance can be interpreted in various ways, such as respecting and celebrating differences, a generally positive attitude towards other groups, the absence of prejudice, and accepting something that is not approved or that is prejudiced [6]. The APA defines tolerance as a person's acceptance of others whose actions, beliefs, physical abilities, religion, customs, ethnicity, and nationality are different from one's own [7]. In the study of Social Psychology, tolerance is often equated with the concept of non-judgment, openness, respect for diversity, or is seen as a generally positive attitude towards other groups [8]. Meanwhile, according to Doorn, tolerance is the acceptance of things that are not approved or disliked so that we can relate and interact better with others [9].

One of the psychological problems that are often experienced by students is intolerance behavior. Intolerance can be interpreted by not respecting differences between others, both in terms of religion, ethnicity, or others, so that it can cause hatred and chaos [5]. If this is allowed, then the possibility of the emergence of social conflicts cannot be dammed and tends to lead to a process of national disintegration. Where students often show a state of difference of opinion and different views, which arise from the students themselves. On the other hand, this also occurs due to the dynamics and social transformation caused by globalization and modernization which has implications for students' attitudes and behavior which causes the values of togetherness and openness to fade.

There are several causes for the emergence of individual intolerance as stated by social psychologists and social scientists, namely: 1) immature mental readiness, so that individuals are easily influenced by things conveyed by others; 2) political inequality that raises speculation that young people do not have adequate access; 3) economic inequality, caused by difficult life; and 4) problems of religious understanding [10].

Intolerance according to the KBBI is the absence of tolerance so it is contrary to tolerance, intolerance is an attitude that refuses, does not respect, does not allow opinions (opinions, views, beliefs, habits, behavior, and so on) that are different or contrary to one's own stance [3]. A similar view by Ceci \& Williams states that this view of intolerance causes acts of violence, oppression, supervision, and exclusion of individuals or groups who are considered to have differences [11]. This intolerance is a phenomenon that will occur as long as humans exist. Humans are different in each individual and this difference is one of the factors that cause intolerance. Intolerance does not only occur in the realm of SARA (ethnicity, religion, race, intergroup), it can also occur in the same SARA group but have different opinions or stances. Intolerance cannot be eliminated as long as humans still exist, but humans can be aware of their intolerance attitudes and behavior, and it is hoped that from this awareness humans can improve their behavior. Minimizing this intolerant attitude does not need to be 
mandatory or forced, but by changing the individual's point of view to being intolerant by explaining and introducing other points of view that are more logical and reasonable. Of course, an assessment to identify individuals with a tendency to behavior intolerance is very necessary, and this can be done with the TAT.

\subsection{Thematic Apperception Test (TAT)}

Thematic Apperception Test is a test tool developed by Christina Morgan and Henry Murray, the theoretical basis of this test is that a human will give a view of his position in an ambiguous problem [12][13][14]. Subconsciously the subject of the TAT will write a "character" analogy of a picture of the problem from his point of view. TAT has a procedure by giving cards containing images of an ambiguous atmosphere and instructing the subject to tell what happened from the picture, in this story the subject will put himself in a position that they think is the same as the point of view they support [15][16].

According to Bellak \& Abrams, there are 30 TAT cards. From these 30 cards, researchers will sort out cards that reflect tolerance and intolerance behavior [17]. The subject will then write down the story from the cards given, the subject is given enough time. The provision of TAT is carried out online or offline through Guidance and Counseling teachers in the schools that are the research sample. To minimize the bias that occurs in the implementation of the TAT analysis, the subjects are given to fill in at their respective homes so as not to be influenced by peer pressure.

\section{METHOD}

This type of research is descriptive research, which means it presents an explanation of the research results obtained. The population of this research is high school/vocational school students in Singaraja City. The research sample was reduced using Morgan's table, and the determination of the sample members was determined by a random sampling technique. There are 7 Senior High Schools/Vocational High Schools in Singaraja, namely Senior High School 1, Senior High School 2, Senior High School 3, Senior High School 4 and Vocational High School 1, Vocational High School 2, and Vocational High School 3. Out of the seven schools that meet the following requirements, researchers reduce the sample using random sampling using a lottery. From this reduction, the authors took 3 schools with a total of 120 respondents.

The method of data collection in this study, using the Thematic Apperception Test (TAT). Data analysis uses categorization of the total score obtained by respondents based on the TAT answers. The procedure of this research consists of : 1) the implementation of data collection is carried out online, 2) respondents who have been obtained from the random sampling method are then given a link to be given the TAT online, 3) the TAT procedure is carried out by providing ambiguous pictures and respondents are directed to make a story that tells the story. can narrate the picture according to what is perceived by the respondent, and 4) the response given is then analyzed. While the procedures for giving the Thematic Apperception Test (TAT) to students are 1) analysis of needs or things that happen to students through the interview process or direct and indirect observations to build report cards; 2) image adjustment to the age of the student or respondent; 3) respondents must answer individually; 4) respondents are asked to tell or narrate the picture according to their imagination and perception of the picture.

\section{RESULT AND DISCUSSION}

The purpose of this study was to describe the tendency of high school students' intolerance behavior by using Thematic Apperception Test (TAT) analysis. Such as the findings of researchers related to the intolerance behavior of students in high school / vocational high school in Singaraja City, namely insulting the color of friends' skin, berating friends who have shortcomings, not wanting to share when a friend is having trouble, being indifferent to the surrounding environment, not wanting to share with others. hear opinions, suggestions, and criticisms from others. In addition, it was also found that students incited other friends not to be friends with people they did not like, were picky about friends, did not obey the rules at school, tended to not respect elders at school, and made unilateral decisions.

With the findings based on observations and interviews with teachers and students at school, the researcher wanted to analyze the intolerance behavior of students using the Thematic Apperception Test (TAT) by utilizing google forms to facilitate online analysis.

The analysis indicators in this study are based on the findings of previous studies, namely, first, according to Qodir, tolerance is influenced by 1) immature mental readiness, so that individuals are easily influenced by things conveyed by others; 2) political inequality that raises speculation that young people do not have adequate access; 3) economic inequality, caused by difficult life; and 4) problems of religious understanding [10]. Second, according to Verkuyten, Adelman \& Yogeeswaran, psychologically, intolerance is divided into three types, namely: (a) Intolerance Prejudice is intolerance caused by rigidity, the narrowness of point of view, and antipathy towards a person or group, (b) Intuitive intolerance is intolerance that arises from the trust. or assumptions without clear evidence from a person or group of people about another person or group, (c) Consultative intolerance is intolerance that interferes with a belief, habit, or behavior that according to a person or group of people violates the values they believe in [8]. 
From the two findings above, it can be seen that the similarities between individuals who have intolerant tendencies are individuals who have prejudiced behavior, namely individuals who are influenced by ideals, ways of thinking, environmental pressures, jealousy, or influences from others without any strong evidence. So in this study, the indicators of Intolerance tendencies used are:

First, prejudice occurs because of the narrow mindset of the individual, this can be seen from the narrative made by the respondent in answering the TAT. Second, jealousy occurs because a group of people feels that their conditions are unfair to other groups of people and a denial arises by blaming other groups for various reasons. Third, insecure individuals are the most easily influenced and have a high probability of running away from problems by blaming others. Fourth, aggressive behavior is behavior that can be physical or non-physical, individuals with aggressive behavior tend to behave intolerantly towards other individuals, especially in satisfying their egos. Fifth, assumptions are ways of thinking that are influenced by the environment and the individuals in the environment, if the environment is potentially intolerant, most of the ways of thinking of individuals in the environment will be the same.

Based on the results of the Thematic Apperception Test (TAT) analysis that has been filled in by the respondents, it is found that the characteristics of intolerance are described as:

Insecure is described as feeling insecure interpersonally. These indicators are interpreted with behaviors such as people pleaser, meaning that someone is trying to be a person that people like, possessive who needs validation from others so that he can feel safe and emotionally comfortable, likes to regulate (bossy), which tends to regulate other people to act accordingly. with his will, self-body shammer that is comparing his body with other people who have an ideal body, focus on his shortcomings usually tend to be low self-esteem and inferior, do not want to leave the comfort zone because conditions outside the current situation will be considered a scary zone and uncomfortable, implicitly showing off and not infrequently they praise themselves by putting others down. The average score of the Thematic Apperception Test (TAT) is $87 \%$, showing manifestations of intolerance.

Aggression is described as an action that intends to injure both verbally and nonverbally against another individual that is intended to harm others. This indicator is interpreted as behavior such as hostile aggression that comes from anger that aims to hurt, damage, or harm. Instrumental aggression aims to injure, damage, or harm, but only as a means to achieve other goals. The average score of the Thematic Apperception Test (TAT) is 75\%, which shows the manifestation of intolerance.
Assumptions are described as assumptions that are accepted as the basis or basis for thinking because they are considered true. The indicator is interpreted as an explicit assumption, which is a statement of truth that is stated clearly, unequivocally, uncomplicatedly, and completely. An implicit assumption is a truth that is not stated clearly but is contained or implied in it. The average Thematic Apperception Test (TAT) score, which is $70 \%$, shows the manifestation of intolerance.

Prejudice is described as a negative judgment or dislike and even hatred towards a group or individual which is manifested through negative attitudes which usually occur due to conflict or dislike of other individuals or groups. These indicators are interpreted as demeaning intellectual behavior, degrading behavior on cultural or individual attributes, and degrading behavior on the morality of individuals or groups who are objects of prejudice. The average score of the Thematic Apperception Test (TAT) is $60 \%$, which shows the manifestation of intolerance.

Jealousy is described as a complex emotion that causes suspicion, anger, fear, or humiliation. These indicators are interpreted as low self-esteem, masterservant mentality, self-destructive behavior, difficulty accepting responsibility, selfishness, blaming others, fear, over-sensitivity, being overly suspicious, and venting anger. The average score of the Thematic Apperception Test (TAT) is 57\%, which shows the manifestation of intolerance.

Based on the calculation of the average attitude indicator of the tendency of intolerance above, the highest to lowest scores can be sorted as follows: insecure by $87 \%$, aggression by $75 \%$, assumptions by $70 \%$, prejudice by $60 \%$, and jealousy by $57 \%$. Thus, the hypothesis is obtained that the Thematic Apperception Test (TAT) analysis can be used to identify individual intolerance behavior tendencies. These findings describe the manifestation of intolerance behavior that is interrelated between one indicator and another. However, it still needs to be seen from the individual dominance factor if experiencing intolerance behavior based on the indicators above.

The above results are in line with the research conducted by Verkuyten, Adelman \& Yogeeswaran [8] The above results are in line with the research conducted by Verkuyten, Adelman \& Yogeeswaran. Psychologically, intolerance is divided into three types, namely: (a) Prejudice Intolerance is intolerance caused by rigidity, narrow perspective, and antipathy towards a person or group, (b) Intuitive intolerance is intolerance that arises from beliefs or assumptions without clear evidence from a person or group of people about another person or group, (c) Consultative intolerance is intolerance that interferes with a belief, habit, or behavior that according to a person or group of people violates values. which they profess. From these findings, 
researchers get mutually supportive results if this intolerance will cause tension and friction from two different parties, tensions arise from sensitive issues involving ethnicity, religion, race, and intergroup (SARA), traditions, beliefs, and customs. Therefore, the urgency to overcome intolerance is very important. A person or group of people who tend towards intolerant behavior choose to keep their mindset and behave intolerantly if there is support or support from groups with the same mindset, this is what makes the authors focus on assessment and identification of intolerant attitudes using TAT analysis.

\section{CONCLUSIONS}

This study aims to describe the tendency of high school students' intolerance behavior by using Thematic Apperception Test (TAT) analysis. Intolerance behavior contains five indicators consisting of prejudice, jealousy, insecurity, aggression, and assumptions. From the reduction of respondents as many as 120 people, data analysis uses categorization of the total score obtained by respondents based on the Thematic Apperception Test answers. In this study, the sample filled out the Thematic Apperception Test online by answering picture questions in the form of stories resulting from self-interpretation of the pictures.

Based on the calculation of the average attitude indicator of the tendency of intolerance, the highest to lowest scores were obtained as follows: insecure by $87 \%$, aggression by $75 \%$, assumptions by $70 \%$, prejudice by $60 \%$, and jealousy by $57 \%$. Thus, the hypothesis is obtained that the Thematic Apperception Test (TAT) analysis can be used to identify individual intolerance behavior tendencies.

\section{REFERENCES}

[1] H. Keller, Optimism. Simon and Schuster, 2012.

[2] E. Christiana, "Pendidikan yang Memanusiakan Manusia," Humaniora, vol. 4, no. 1, p. 398, 2013, doi: 10.21512/humaniora.v4i1.3450.

[3] T. P. K. P. Bahasa, Kamus Bahasa Indonesia. 2008.

[4] B. News, "Wajib jilbab bagi siswi non-Muslim di Padang: "Sekolah negeri cenderung gagal terapkan kebhinekaan,”' BBC News, Jan. 26, 2021.

[5] S. Amir and A. Hakim, "Pencegahan Sikap Intoleransi Pada Siswa Melalui Penguatan Pendidikan Pancasila," Semin. Nas. Pendidik. Dasar, vol. 1, pp. 52-62, 2018, [Online]. Available: https://repository.bbg.ac.id/bitstream/680/1/008_S AIFUL_AMIR.pdf.

[6] M. Verkuyten and L. Slooter, "Tolerance of Muslim beliefs and practices: Age related differences and context effects," Int. J. Behav. Dev., vol. 31, no. 5, pp. 467-477, 2007, [Online]. Available: http://citeseerx.ist.psu.edu/viewdoc/download?doi= 10.1.1.907.6129\&rep=rep1\&type $=$ pdf.

[7] M. A. M. Nizah, J. A. Jawan, S. Singh, L. D. Singh, and K. H. K. Samsu, "Framing Ethnic Tolerance, Political Tolerance and Voting Behaviour," Mediterr. J. Soc. Sci., vol. 6, no. 4, p. 365, 2015.

[8] M. Verkuyten and K. Yogeeswaran, "The Social Psychology of Intergroup Toleration: A Roadmap for Theory and Research," Personal. Soc. Psychol. Rev., vol. 21, no. 1, pp. 72-96, 2017.

[9] M. van Doorn, "Tolerance," Sociopedia.isa, vol. 47, no. 3, pp. 220-243, 2013, [Online]. Available: https://doi.org/10.1177/0095399713509530.

[10] Z. Qodir, “Kaum Muda, Intoleransi, dan Radikalisme Agama,” J. Stud. Pemuda, vol. 5, no. 1, pp. 429-445, 2016.

[11] M. Verkuyten, L. Adelman, and K. Yogeeswaran, "The Psychology of Intolerance: Unpacking Diverse Understandings of Intolerance," Curr. Dir. Psychol. Sci., vol. 29, no. 5, pp. 467-472, 2020.

[12] M. N. McCredie and L. C. Morey, "Convergence between Thematic Apperception Test (TAT) and self-report: Another look at some old questions," J. Clin. Psychol., vol. 75, no. 10, pp. 1838-1849, 2019.

[13] M. J. Hoffarth, "From achievement to power: David C. McClelland, McBer \& Company, and the business of the Thematic Apperception Test (TAT), 1962-1985," J. Hist. Behav. Sci., vol. 56, no. 3, pp. 153-168, 2020.

[14] G. E. Nissley and E. DeFreese, "Thematic Apperception Test," Wiley Encycl. Personal. Individ. Differ. Meas. Assess., pp. 381-385, 2020.

[15] O. Calderon and R. Kupferberg, "Stories Children Tell: Should the Thematic Apperception Test be Included in Psychoeducational Assessments?," Contemp. Sch. Psychol., pp. 1-11, 2021.

[16] H. Wagatsuma and G. A. De Vos, "Appendix B. Thematic Apperception Test," in Heritage of Endurance, University of California Press, 2020, pp. $475-476$.

[17] S. P. Widjanarko, "Gambaran Kebutuhan Psikologis Remaja Penyandang Tuna Rungu Diungkap dengan Thematic Apperception Testb (TAT)," Universitas Sanata Dharma, 2014. 